\title{
1 Exceptional Libraries and Distinctive Architecture: Celebrating Reuse
}

\begin{abstract}
This chapter traces some of the origins, developments and newer tendencies in reuse architecture from the perspective of the architect. Furthermore, it examines possible sustainability issues and qualities, beyond the obvious recycling aspect, inherently rooted in the practice of reuse architecture. The chapter also provides insight into some of the practical aspects of conversion and adaptive reuse from the planning stage at the drawing board to the reality of the building site, while maintaining a theoretical underpinning of this praxis, which the author considers to be a genre of its own. Accompanying the theoretical and practical overview, the chapter casts a critical eye over the relationship of formalised historic preservation methods and traditions in relation to the growth and popularity of reuse architecture and questions its future trajectory.
\end{abstract}

Keywords: Library buildings; Buildings - Protection; Buildings - Remodelling for other use; Sustainability

\section{Introduction}

Formerly seen as a menial architectural task, adaptive reuse has come into its own. It is no longer a secret, and certainly no longer a novel idea, that the architecture of adaptive reuse is, in terms of architectural creativity, beauty and importance, in no way inferior to designing and building a brand-new building (Hauke and Werner 2011).

Architecture incorporating existing structures has been experiencing an enormous boom and an increase in prestige for some time, and as claimed in this chapter, has become an architectural genre of its own. Preservation has traditionally been the driving factor for maintaining historic structures. Until recently, the reuse of existing buildings almost always meant dealing with historically listed buildings. These days adaptive reuse of older structures is not only in vogue but makes up a major part of the current construction industry's business. Surprisingly, such projects are to a large degree no longer using only historical listed buildings. What has changed? 


\section{Continuity and Sustainability}

For investors, clients and architects. the large increase in construction projects using existing fabric certainly owes much of its success to the growing number of inspiring architectural examples of reuse architecture. The attention attracted by these projects has increased the acceptance of reuse and in turn the market. Small and large architectural firms, as well as clients from the private and public sector, municipalities and cities, have found the strategy of adaptive reuse successful on several levels.

It can be said with certainty that the combination of old and new creates an unmistakable identity and radiates uniqueness. Not only has the acceptance of reuse design increased, the socially relevant trends for sustainability have become dramatically important and are reflected in the desire for reuse architecture. People like to carry bags made from used truck tarpaulins and they like to live and work in buildings with history and patina.

This however goes beyond trendy fashion. The preservation and reuse of buildings represent an urban and social continuity which in an increasingly demographically fluid society is becoming progressively more important. Not only maintaining the appearance of an old building in the city, but the singular quality of the interior spaces, possessing a strong architectural identification, represents a valuable anchor and counterpoint to the increasingly virtual spaces of our everyday work. This is especially true in library design. The spread of the digitised virtual world, exponentially heightened forced by the corona crisis, certainly underlines the phenomenon of an inner desire for a real space. Differing from a virtual space, a room with history can be experienced simultaneously with all the senses. The number and divergent ages of users that enjoy the quality and identity these strong spaces exude, indicate that their real and haptic qualities are important to everybody.

In addition to perceptual or soft values, the aspect of economic efficiency in the maintenance or even conversion of existing buildings should not be overlooked. It is no longer the case that demolishing and rebuilding are less expensive than maintaining and reusing. Many project developers have successfully facilitated cost reductions. The previous creed of tabula rasa has long been off the table. The increased demolition and disposal costs of building rubble, especially the disposal costs of contaminated building materials, have become not only dramatically greater but ecologically questionable. With ecology and economy in mind, a new reality of perceiving an energy balance in the built environment has emerged. The new reality is clearly represented by the increasing recognition and consideration of total energy consumption including grey energy. Grey energy consists of the sum of energy expended in the initial creation plus the 
energy expended through demolition and disposal as well as the energy needed to rebuild. The holistic consideration of energy consumption has become the relevant energy factor and argument for reuse.

Finally, thanks to new insulation materials and clever building physics solutions, reused old buildings no longer must have a lower energy performance then a new building, provided that the architect and client understand their craft well and are able to implement the necessary planning considerations successfully.

\section{Understanding an Existing Building}

For the success of a reuse project, it is essential that the architect studies and understands everything about the existing building and its history down to the smallest detail. Here is where the design path between new construction and reuse strategies clearly diverges. A sensible investment in reusing an existing building cannot afford to omit the in-depth understanding and documenting of the existing structure in a multifaceted and detailed manner.

To create a through and accurate investigation of the existing building, it is necessary to analyse the entire structure, including the changes over time. The examination requires, for example, an in-depth study of the intellectual origin and related art and architectural history, the past uses and their impact, the structural and technical systems and their possible alterations, the construction materials used and the geometric shape and possible deformations of the building as well as a thorough damage and contamination assessment. It is ultimately completely irrelevant whether the existing structure is an architectural landmark, a historic monument, or an ordinary building. Of course, a historic building is usually more complex to investigate, but historic building or not, only from a deep understanding of the built material is it possible to create a successful and cost-efficient reuse project and avoid possibly serious difficulties.

The sometimes costly and time-consuming but necessary examinations, which often need special experts, are best done at the very beginning of the project. Unfortunately, many clients shy away from these investments, thinking that they can save money. This is almost always a fallacy, and in the long run one that can be expensive and risky. Architects are often hesitant to request their clients to contract the studies up front, mostly out of concern that the uncertainties, time and cost will act as a deterrent from the outset and possibly endanger the project. Nonetheless, unforeseen costly investments can only be best identified and averted by thorough studies and analyses at an early stage. 
Furthermore, the profound understanding of the existing building is a prerequisite before the architect even begins to design. Unfortunately, some architects may approach a reuse design task with un-reflected formal wishes and personal tastes from the outset, without really understanding the existing structure. Such a design procedure can lead to superfluous interventions that quickly become unnecessarily complex and costly. Once the course is set, there is often no way back. The approach needs to be different. From the very beginning, the designer needs to perceive the existing building as an ally, not as a foe that needs to be subjugated! The true task is about working with the structure, not against it.

It seems self-evident that an existing building did not simply sprout out of the ground or fall from the sky; it has a past. When considering an old building, it needs to be understood that at some distant time in the past someone had the need or dream of building a structure on that very spot, at that very time for purposes that they clearly understood. The existing structure therefore represents a manifestation of those thoughts, anchored in time and place. These things all form an inner logic that flowed into the design and ultimately the realisation of the building. The existing building substance is therefore evidence of the original structure, ground down by use and stained by time to become the present entity. Perhaps the combination of all factors contributes what should be considered to the true structure.

Finally, when designing within an existing building, it is necessary for the architect to understand how to develop an architectural synthesis from all the information gathered in order to arrive at a good design. This requires not only an understanding and respect for the existing structure including its constraints, but the necessary architectural talent, expertise and skill.

\section{Constraints}

As well as the many qualities worth maintaining, old buildings present many constraints, restrictions and difficulties. It is simply a fact that not every type of new use is compatible with an old structure. The possibilities and advantages but also the disadvantages and difficulties need to be carefully considered beforehand.

In the design for a conversion or reuse of an old building, it is not the form follows function mantra that dictates the strategy, but the existing structure itself. By definition, a building legacy already exists prior to the new design or changed usage. The sequence of design is all about integrating the new functions into the existing fabric, not the other way around. Often modern building requirements and needs must be adapted to comply with the existing structure. 
Sometimes new functions need to be redefined to become compatible. Initially that sounds restrictive, and sometimes it is. First impressions, however, are often deceptive. It seems a contradiction, but often good ideas are made possible as a result of overcoming seemingly inflexible restrictions.

When dealing with an old building. it is always necessary to define the approach on a case-by-case basis. The simple fact is that no two old buildings are alike. Careful study is needed to determine just how much new insertion is compatible with the old. On the other hand, it is important to establish that much of the contemporary is required to breathe new life into the old. A careful, step-bystep approach does not mean that the new has to play an inferior or a secondary role. The degree and intensity of change and intervention need to be carefully researched and tested.

A typical problem, especially when it comes to library construction, is the structural capacity of old floors. The timber beam is a typical floor construction of older buildings. Unfortunately, timber floors have only a limited load-bearing capacity and are often deformed from years of use. The prescribed load capacity to carry the heavy bookshelves required for library usage can quickly become a problem for a wooden structure. It is possible to reinforce timber beams or even replace them with a steel or concrete construction. In listed buildings, however, this is not usually permissible. An alternative can be to arrange areas in such a way that those with limited load-bearing capacity are not used for heavy loads and thus preserved. Areas with heavy load requirements can be moved to less historically sensitive zones, or areas with a modern construction.

Material deficiencies in older structures can be of major concern. Wood rot and insect infestation are common problems with wooden components. In old masonry structures, damp walls and mildew are not uncommon, often due to a lack of proper waterproofing. Cracks from settlement or brick damage due to a lack of frost resistance are further typical masonry problems. Contamination has become a growing and complex problem. Well-meant renovations in the 1970s and 1980s with toxic wood preservatives have caused dangerous chemical contamination. Added insulation for energy conservation, with carcinogenic micromineral fibres as well as asbestos in cladding, and fillers are also not uncommon. Furthermore, soil contamination from previous polluting uses can lead to costly correction.

Another important consideration is the effect of new use on the existing building's time-tested internal microclimate. A new and different use for a building, as well as modern insulation and increased wind and waterproofing, causes the building's physical nature to change dramatically. Older buildings are traditionally less airtight and less insulated. Modern energy saving demands with hermetic construction standards create a completely different environment within the building. It has become ever more important that correct understanding of 
building physics, at the outset and planning stage, is necessary for a successful renovation and a healthy future for the building.

Last but not least, fire protection often presents an all-encompassing difficulty especially with timber floors or wooden construction. A change in use frequently causes the loss of former rights, in which case the old building must comply with modern building codes and restrictions. Especially in an historically listed building, modern fire regulations can sometimes be met only through special exceptions and limitations which in some cases might be prohibitive.

All issues, however, can be solved if identified early on and creatively and intelligently dealt with. The unexpected puts a strain on the budget and scheduling. One thing is certain when dealing with old structures. Unexpected things always happen.

\section{Respect for the Old}

As well as a deep understanding of the old structure, the client and the architect need to respect the existing materials, the original intentions of the builder, and the traces of time, uses and events.

Unfortunately, in the world of real estate investment, it is not uncommon to use an old façade as a feel nice image while gutting the interior and replacing it with a new building meeting modern standards and expectations. Gutting a building's interior is like a lobotomy in that it erases the past and reduces history to a thin veneer in the streetscape. Fortunately, overall, approaches are more enlightened today. Investors are discovering the power and marketability of existing buildings as a contextual whole.

It is not just the handsome architectural styles, the noble room heights, the decorative stucco, sculptural mouldings or haptic materiality that make an old building special. It is to a great extent the atmosphere of the old building, with its own inner life and story to tell that exude an other-worldly value of age. All of these make an old structure individual and unique. The ageing of materials is a product of all the events that have occurred in and around the building over time. Like archaeological strata, the accumulation of transformations creates the layers of the building's history that are structurally and temporally interrelated. The building's historical aura or story, however, is not always one of harmony, rather the opposite. The test of time often erodes the original clarity and well-tempered design. Ad hoc changes and unforeseen events gnaw at the intactness of a structure. The narrative power of an old building is a treasure that has a lot to give, but unfortunately can easily be fleeting. 
The aura of age is like a venerable but gnarled, scoured and leathery bubble that has endured the passage of time, weather and use. It is also, however, a delicate and sensitive bubble that bursts and collapses into nothingness when poked at too much, and once lost it can never be regained. Here is where the architect needs to tread with care and discipline.

An old building is simply not a new building. It is better to accept this from the start. It does not mean that restoration, improvements and changes are not possible or even necessary. However, an attempt to convert an old building into a new one or to impose unnecessary new building standards can do more harm than good. It is easy to understand, that having invested in the purchase and renovation of a building, an owner may want it to acquire a new splendour. Too much face-lifting can lead to the destruction of the unique charm of an old building. Slick perfection destroys the emotional and historical characteristics that make the original so special. This has to do with the authenticity of the building and its material which is expressed through the patina of time and the story of its use. If original characteristics are cleaned up, the authenticity is irretrievably lost. The vision and insight of critics such as John Ruskin (1819-1900), who in the $19^{\text {th }}$ century argued that only authentic built material contains true artistic value and its removal or alteration destroys it completely, have validity to this day (Ruskin 1849).

To become historically listed, a building must be determined by the responsible authorities to have a heritage value worthy of protection by elevating it to listed status. Because heritage value is also a cultural value, the goal of historic preservation is to maintain the listed building for society for as long as possible. The term architectural heritage refers to the inheritance of a built environment accompanied by a responsibility for maintenance and preservation. But not all special, wonderful and beautiful buildings are listed. Are unlisted buildings necessarily of a lesser value? Such buildings together with less obvious, ordinary structures are often very much worth saving and maintaining. The lack of recognition of architectural heritage is not a denial of the value of preservation. The historian and preservation specialist, Alois Riegl, determined that listed historic buildings all possessed special values to differing degrees (Riegl 1903). These he determined as "historical value, artistic value, age value, commemorative value, use value, and newness value". Even if a structure is not listed, it still possesses architectural value as well as the other values already discussed.

In maintaining or reusing an old building, its intrinsic values can only continue to exist if the architect and the investor pay adequate attention and respect to conserving them. That is what makes a successful reuse project special; everything else is purely recycling. 


\section{Fresh Approaches to Tradition}

Not only does the old need to be respected and its story told; the new also has a story to tell! To do this, the new needs to be able to meet the old at eye level. Respect does not mean subservience. In 1964, the Venice Charter for the conservation and restoration of monuments and sites aimed to establish international standards and guidelines in the conservation and restoration of historic monuments (https://www.icomos.org/charters/venice_e.pdf). Within the charter, conservation professionals agreed that new extensions or alterations need to be clearly distinguished through separation or contrast. An architectural distancing of old and new was thus put into practice and is a mantra to this day. Since then, there have been many important charters, amending and extending universal understanding and practice of historic preservation, but without a doubt the Charter of 1964 remains a keystone of modern historic preservation. After years of practice however, distancing, like the Charter itself, has become rather dogmatic. Standard solutions, such as glass links separating old and new, emerged early on, and have become so customary that their appropriateness is almost no longer questioned.

Another way of distinguishing between old and new is the use of modern materials. The honesty of steel and glass construction, as a contrast to the old, was for many years an accepted method. If a strong visual contrast was deemed to be to dominating, then the opposite happened and too often the new architectural work was expected to be subservient to the old and barely seen; it therefore lacked confidence and pandered to the old. The results were often uncomfortable combinations and historical anomalies. Times have changed and modern reuse architecture has come of age. In the search for a distinction of old and new, a certain casual, but healthy disrespect has emerged. Misbehaving with an appropriate, well-researched impishness could perhaps summarise the success of new, self-confident approaches, which are in no way based on ignorance or naivety. Through a thorough understanding of the existing structure, they combine new building requirements and modern design with the old, without any destruction of original material. The result is a modern form of contrast, based on a holistic combination of old and new which reads as a new entity. To summarise Aristotle, the whole is greater than the sum of its parts.

All of this is not new at all. As Georg Dehio, one of the most important thinkers in historic conservation in Europe, explained in 1905:

... if the needs of the new era necessitate a change or an addition, it is really not clear for what purpose and with what right one should hide this origin. Showing false antiquities is neither true art nor true historic preservation. (Dehio 1914) 
Dehio went on to say, however, that "a clear, healthy and modern German architecture needs to be developed".

Dehio's view of a nationalistic architecture from a current point of view is dubious and certainly outdated, but his call for a side-by-side context of old and new has given rise to a wide range of successful reuse architectural solutions with a new, readable, creative diversity and an attitude of self-confident Weiterbauen/ further building. Weiterbauen is a design attitude that likens stacking epochs upon or next to one another. It empathetically adapts to the existing building with respect but without an inhibiting reverence. It is a method which preserves the old by retaining it within the new.

Perhaps with the demise of postmodernity and the abandonment of deconstructivism, a path is open for innovative solutions which will further stimulate conservation and preservation along with the development of new methods for dealing with the ever-increasing range of new types of existing buildings worth keeping.

\section{An Archaeological Way Forward?}

Anyone who knows anything about history and architecture knows that there is practically no such thing as stylistic purity. All through history, buildings have been destroyed, rebuilt, modified, expanded and reused. Some structures were used as quarries for other buildings and many were supplemented and modified with materials harvested from other buildings. It is guaranteed that if one looks closely at an old church or castle, there is a conglomerate of different ages, building materials and architectural styles. Reuse, recycle and remodel are perhaps trendy terms, but they describe an ancient architectural practice. The question is, was the end result better?

In this book, the wide range of reused buildings, of all ages and types, which have become successful, vital and fascinating new libraries answers that question with an emphatic yes. It is not important if the building was a former grocery store, barn or precious monument, all have great potential and offer a sustainable trajectory for a social and ecological form of building.

Under new economic and ecological pressure, a growing number of buildings, or parts of structures, are being reused. High-rise buildings, schools and office buildings are being partially maintained and recycled through the dismantling of the shell and refitting with modern energy-efficient claddings. This not only represents a huge volume of construction in the near future, but it also represents new design options. The established historic preservation authorities for 
the most part are neither involved with this type of reuse nor do they seem to see it as an area worth investigating.

In his essay In Hülle und Fülle / In Abundance, Andreas Hild describes the traditional tried-and-tested goals of historic preservation as "making history tangible, keeping tradition alive and preserving substance” (Hild 2013). However, based on ecological and financial conservation criteria, Hild states that the new and sheer "abundance of potential monuments" creates a wholly new framework, altered conditions and thus also new challenges for historic preservation. The future requires that historic preservation authorities be able to "within a social discourse, form majorities to formulate requirements for the appropriation and also the adaptation of our building stock" (Hild 2013).

It remains to be seen whether building protection policies and processes can meet the new requirements. The ecological and social necessity to convert cities' vast amounts of outdated building stock, especially from the post-war period, to a healthy and viable future use is clearly increasing. There is great potential and strength in seizing the opportunity to form a new approach, an architectural acceptance of the many-layered nature of architectural heritage across time.

\section{Conclusion}

The importance of reusing existing buildings is being increasingly recognised as outlined above. Key to a successful reuse project is finding an appropriate new occupant for the building and the projects described in this book show the adaptability of libraries, particularly in the digital age with less dependence on print. Libraries are places of learning, culture and community and, furthermore, have embraced the sustainability agenda enthusiastically. They are a perfect fit with old buildings. Such buildings are often strategically located, they encapsulate the history of their community and reusing them supports the three pillars of sustainability: economic, environmental and social.

The future of libraries, and in particular libraries subscribing to the ethos of reuse architecture, combining the new with the old, seems secure. When I look at Étienne-Louis Boullée's famous drawing of the interior of his public library for the Bibliothèque du Roi in Paris (1785), said to be inspired by Raphael's fresco The School of Athens (1509/1511), I do not see a reverent and quiet space with silent people studying alone at desks, but rather I see an active and social place with an incredible spatial identity. It is a place for meeting, discourse and interaction as if on the stage of urbanity. No wonder the image is almost iconographic for library space. It is less well known but perhaps no coincidence that Boullée's 
library design was also an example of reuse architecture; it transformed the old Royal Library while maintaining most of the structure and converting the exterior courtyard to form the main interior space.

It is time for a paradigm shift back to the older more sustainable attitude of maintaining and reusing. Reuse architecture must be the first choice and demolition and new construction seen only as a second option. In working with the built heritage and historic buildings in general, the old needs to be respected and maintained but enhanced with a confident and lively relationship, both as a definition of the past and an opportunity for the future.

\section{References}

Dehio, Georg. 1914. Denkmalschutz und Denkmalpflege im neunzehnten Jahrhundert: 1905 Festrede an der Kaiser-Wilhelms-Universität zu Straßburg, den 27. Januar 1905. http:// www.deutschestextarchiv.de/book/view/dehio_aufsaetze_1914? $p=323$

Hauke, Petra, and Klaus Ulrich Werner, eds. 2011. Secondhand - aber exzellent! Bibliotheken bauen im Bestand. Bad Honnef: Bock + Herchen. Contains among others: Niess, Robert: "Dieses Bedürfnis nach Ort, nach Raum, nach Würde ... Interview mit dem Architekten Robert Niess, Berlin”, 18-45. https://edoc.hu-berlin.de/handle/18452/59

Hild, Andreas. 2013. “In Hülle und Fülle: Zur Zukunft des Denkmalschutzes.” Der Architekt, (April 19, 2013). http://derarchitektbda.de/in-hulle-und-fulle/

Riegl, Alois. 1903. Der moderne Denkmalkultus, sein Wesen, seine Entstehung: Einleitung zum Denkmalschutzgesetz. Wien: W. Braumüller.

Ruskin, John. 1849. The Seven Lamps of Architecture. London: Smith, Elder, and Co. 